\title{
Novel inclusion of engineered nanoparticles in horticultural sectors
}

\begin{abstract}
Nanoparticles, which are omnipresent in the environment, make their easy way within living systems where their effect can be positive, negative, or neutral. A positive result on plants shows better germination rate and plant growth whereas negative result exhibits growth inhibition, cell damage or deterioration, etc. All these phenomena depend upon the plant species, types of nanoparticles, the concentration of the nanoparticles as well as the nature of the medium. Understanding the nature of interactions between engineered nanoparticles and plants is crucial in the comprehension of the impact of nanotechnology on the environment and agriculture with a focus on toxicity concerns, plant disease treatment, and genetic engineering. In this perspective, the effect of engineered nanoparticles on horticultural plant species will enrich our knowledge about the benefits or risks of these nanoparticles on the balance of the ecosystem namely their mobility, reactivity, toxicity, and persistency in the living system as well as to open a new era to involve different nanoparticles in crop production and overall management of agricultural techniques in near future.
\end{abstract}

Keywords: horticultural plant species, crop production, genetic engineering
Volume 4 Issue 4 - 2020

\author{
Anindita Dey, ${ }^{1,2}$ Papiya Nandy² \\ 'Department of Botany, Asutosh College, University of Calcutta, \\ India \\ ${ }^{2}$ Centre for Interdisciplinary Research and Education, India
}

Correspondence: Papiya Nandy, Centre for Interdisciplinary Research and Education, India, Email pnandy0@gmail.com

Received: July 07, 2020 | Published: August 03, 2020

\section{Applications of nanoparticles in horticulture}

In recent decade different engineered nanoparticles (ENPs) are used in a variety of biological systems like fluorescent biological labels, ${ }^{1}$ gene and drug delivery, ${ }^{2,3}$ bio-detection of pathogens, ${ }^{4}$ detection of proteins, ${ }^{5-7}$ probing of DNA structure and in tissue engineering..$^{8-10}$ Nowadays various ENPs are also widely used in agricultural purposes as nano-fertilizers (NFs), nano-pesticides, nano-herbicides, nanosensors, etc. ${ }^{11-15}$ Increasing market demand and commercial value of chemical fertilizer catch interest on the scientist to prepare a modified, targeted, NFs which are eco-friendly and much facile for plants to take up and can be modified to be time-released. ${ }^{16-18}$ During the design of NFs beside plant protection and nutrients, one should keep in mind the side effect of these ENPs on the environment as all the ENPs used to prepare NFs are finally released in our ecosystem.

NFs enters within the plant system through stomal opening, lenticels, and root system and enhance the overall nutrient use efficiency (NUE) ${ }^{19}$ Nano-agrochemicals also create attentions to agriculturist for their positive effect on hydroponic plant culture. ${ }^{20}$ However, NFs have some advantages over chemical fertilizers and nano-agrochemicals. Alternative to chemical fertilizer, NFs required in very low amounts, easy to use, cost-effective, high nutrient use efficiency, supply macro, and micronutrients which usually soil lacks. ${ }^{21}$ The most popular ENPs used recently as NFs are carbon nanotube (CNTs), zinc nano fertilizer, nanoporous zeolite, boron nano, etc. Among all other ENPs, the Penetration capability of CNTs through hard seed coat enhances the germination percentage, shoot growth, and overall crop plant biomass production..$^{22,23}$ The bioavailability and bio-degradation capability of CNTs also make their wide use in NFs production. ${ }^{24,25}$

ENPs can be used to prepare pesticides, herbicides, fungicides for securing crop production and are more beneficial than conventional plant protection techniques that have been used in large-scale and in over-dose. ${ }^{26}$ Nano herbicide and nano pesticides are also much effective in crop plants than the market available insecticide killers. ${ }^{27,28}$
At present agricultural practices, nano-agrochemicals are very common as the emerging category of contaminants generates a negative impact on field crops. Alternatively, an emerging solution has developed by involving nanotechnology to prepare nano pesticides and NFs. ${ }^{29}$ Moving to a broader concept of nano-enabled technology and building on the experience from other sectors (e.g., food science, nanometrology) will be more valuable to support the development of more sustainable agrochemicals. ${ }^{20} \mathrm{NFs}$ have more availability to plants as they can enter easily through the nano-pores and stomatal openings in plant leaves. The deep insertion of ENPs within the plant body leads to higher nutrient use efficiency (NUE).$^{30}$ The higher NUE and lesser nutrient loss of NFs lead to 5-17\% higher productivity and also improve the nutritional quality of horticultural crops. ${ }^{31}$

Some ENPs also can enhance stress tolerance capability that sometimes helps farmers to produce crops in the adverse situation also. $^{32}$

Very recently green synthesized ENPs are also involved in horticultural sectors because of their eco-friendly nature and easy to process compared to the other routes of ENPs synthesis. ${ }^{33,34}$

Some ENPs viz. oxidized multiwalled carbon nanotubes (OMCNTs), hydroxyapatite NPs (HAP), gold NPs, silver NPs, etc. are directly interacted with seeds of vegetables or flowering plants and remarkably enhance seed germination rate, overall plant growth and biomass production. ${ }^{35,36}$

Nanosensor-based global positioning system (GPS) is now popularly used throughout the seasons for real-time monitoring of cultivated fields globally. ${ }^{37}$

\section{Pros \& cons}

The applications of ENPs in horticultural sectors have raised many positive impacts and also some risk factors. Positive results include three times increase in nutrient use efficiency (NUE), 80-100 times less requirement to chemical fertilizers, 10 times more stress-tolerant 
by the crops, Complete bio-sourced, so eco-friendly, 30\% more nutrient mobilization by the plants and $17-54 \%$ improvement in the crop yield. ${ }^{20,21}$ For monitoring the controlled release mechanism in the cultivated fields, the network of wireless nano-sensors is very helpful and cost-effective also.

Minute dose with the presence of more active ingredients in nano-formulated plant protective samples not only protect plants against pests but also enhance subsequent crop loss. ${ }^{38-41}$ However, all the ENPs related treatment are dose-dependent. An extra dose may cause germination hindrance, reduction in plant growth, and overall crop production directly and also health hazards like tissue damage, high blood pressure, gastrointestinal problems, etc. to the consumers indirectly. ${ }^{42-44}$ Though ENPs are used in minute concentration the mishandling of preparations and long-term use may cause the release of ENPs in the environment causing environmental pollution to some extent such as water, soil, and air pollution. ${ }^{42}$

\section{Concluding remarks}

While ENPs are being used in a variety of ways to tackle biorelated issues, a possible area of wide ramification is being neglected due to a lack of relevant technology and understanding. The use of nanoparticles in agricultural sectors has been explored by researchers a few years ago and very recently its implementation in the horticultural sectors improves the production rate of vegetables, flowers, and other essential crop plants to meet the huge demand of the growing population.

Interactions between plants and nanoparticles deserve a more in-depth investigation on many fronts, such as uptake potential of different plant species, mechanisms of uptake, translocation, and the interactions between the particles with plant tissue at the cellular level. However, soon, the exploration of various ENPs in horticultural sectors encourages farmers to a green revolution with negligible farming risks and insignificant side effects.

\section{Funding}

The authors did not receive any funding for this work from any source.

\section{Acknowledgments}

None.

\section{Conflicts of interest}

The authors have no conflicts to declare.

\section{References}

1. M Bruchez, M Moronne, P Gin, et al, Semiconductor nanocrystals as fluorescent biological labels, Semiconductor Nanocrystals as Fluorescent Biological Labels. Science. 1998; 281:2013-2016.

2. S Wang, N Mamedova, NAKotov, et al, Antigen/antibody immunocomplex from CdTe nanoparticle bioconjugates. Nano Letters. 2002;2:817-822.

3. C Mah, I Zolotukhin, TJ Fraites, et al, Improved method of recombinant AAV2 delivery for systemic targeted gene therapy. Mol Therapy. 2000;6(1):106-112.

4. WCW Chan, SM. Nie, Quantum dot bioconjugates for ultrasensitive nonisotopic detection. Science. 1998;281:2016-2018.

5. D Panatarotto, CD Prtidos, J Hoebeke, et al. Immunization with peptidefunctionalized carbon nanotubes enhances virus-specific neutralizing antibody responses. Chem Biol. 2003;10:961-966.
6. RL Edelstein, CR Tamanaha, PE Sheehan, et al. The BARC biosensor applied to the detection of biological warfare agents. Biosens Bioe lectron. 2000;14:805-813.

7. JM Nam, CC Thaxton, C Mirkin, Nanoparticle-based bio-bar codes for the ultrasensitive detection of proteins. Science. 2000;301:1884-1886.

8. R Mahatab, JP Rogers, CJ Murphy. Protein-sized quantum dot luminescence can distinguish between "Straight", "Bent", and "Kinked" Oligonucleotides. J am Chem Soc. 1995;117:9099-9100.

9. J Ma, H Wong, LB Kong, et al. Biomimetic processing of nanocrystallite bioactive apatite coating on titanium. Nanotechnology. 2003;14:619-623.

10. de la Isla, W Brostow, B Bujard, et al. Nanohybrid scratch resistant coating for teeth and bone viscoelasticity manifested in tribology. Mat Resr Innovat. 2003;7:110-114.

11. He X, Deng H, Hwang HM. The current application of nanotechnology in food and agriculture. J Food Drug Anal. 2018;27:1-21.

12. Khan MR, Rizvi TF. Nanotechnology: Scope and application in plant disease management. Plant Pathol J. 2014;13:214-231.

13. Lv M, Liu Y, Geng JH, et al. Engineering nanomaterials-based biosensors for food safety detection. Biosens Bioelectron. 2018;106: 122-128.

14. Ghormade V, Deshpande MV, Paknikar KM. Perspectives for nanobiotechnology enabled protection and nutrition of plants. Biotechnol Adv. 2011;29:792-803.

15. Kwak SY, Wong MH, Lew TTS, et al. Nanosensor technology applied to living plant systems. Annu Rev Anal Chem. 2017;10:113-140.

16. Dwivedi S, Saquib Q, Al-Khedhairy AA, et al. Understanding the role of nanomaterials in agriculture. In microbial inoculants in sustainable agricultural productivity, In: Singh DP, Singh HB, et al. editors. Springer: New Delhi, India, 2016;271-288.

17. Prasad R, Bhattacharyya A, Nguyen QD. Nanotechnology in sustainable agriculture: recent developments, challenges, and perspectives, front. Microbiol. 2017;8:1014.

18. Vermeulen SJ, Aggarwal PK, Ainslie A, et al. Options for support to agriculture and food security under climate change. Environ Sci Policy. 2012;15:136-144.

19. Gogos A, Knauer K, Bucheli TD. Nanomaterials in plant protection and fertilization: Current state, foreseen applications, and research priorities. $J$ Agril Food Chem. 2012;60:9781-9792.

20. Kale AP, Gawade SN. Studies on nanoparticle induced nutrient use efficiency of fertilizer and crop productivity. Green Chem Technol Lett. 2016;2:88-92.

21. Sabir A, Yazar K, Sabir F, et al. Vine growth, yield, berry quality attributes and leaf nutrient content of grapevines as influenced by seaweed extract (Ascophyllum nodosum) and nanosize fertilizer pulverizations. Scientia horticulturae. 2014;175:1-8.

22. M Khodakovskaya, E Dervishi, M Mahmood, Carbon Nanotubes induce growth enhancement of tobacco cells. ACS Nano. 2009;3(10):3221-3227.

23. Mondal A, Basu R, Das S. et al. Beneficial role of carbon nanotubes on mustard plant growth: an agricultural prospect. $J$ Nanopart Res. 2011;13:4519.

24. N Wong, S Kam, HJ Dai. Carbon nanotubes as intracellular protein transporters: generality and biological functionality. J Am Chem Soc. 2005;127:6021-6026.

25. MR McDevitt, D Chattopadhyay, BJ Kappel, et al. Scheinberg Tumor targeting with antibody functionalized radiolabelled carbon nanotubes. $J$ Nucl Med. 2007;4:1180-1189.

26. Solanki P, Bhargava A, Chhipa H, et al. Nano-fertilizersand their smart delivery system. In Nanotechnologies in Food and Agriculture. In: Rai M, Ribeiro C, editors. Springer: Cham, Switzerland, 2015;81-101. 
27. Li SX, Wang ZH, Miao YF, et al. Soil organic nitrogen and its contribution to crop production. J Integr Agric. 2014;13:2061-2080.

28. Subramanian KS, Manikandan A, Thirunavukkarasu M, et al. Nanofertilizers for balanced crop nutrition. In Nanotechnologies in Food and Agriculture. In: Rai M, Ribeiro C, editors. Springer: Cham, Switzerland, 2015;69-80.

29. Nuruzzaman M, Rahman MM, Liu YJ, et al. Nanoencapsulation, nanoguard for pesticides: A new window for safe application. J Agric Food Chem. 2016;64:1447-1483.

30. Subramanian KS, Manikandan A, Thirunavukkarasu M, et al. Nanofertilizers for balanced crop nutrition. In Nanotechnologies in Food and Agriculture. In: Rai M, Ribeiro C, editors. Springer: Cham, Switzerland, 2015;69-80.

31. Abdel-Aziz HMM, Hasaneen MNA, Omer AM. Nano chitosan-NPK fertilizer enhances the growth and productivity of wheat plants grown in sandy soil. Span J Agric Res. 2016;14:17.

32. Onaga G, Kerstin W. Advances in plant tolerance to biotic stresses. In Plant Genomics; Abdurakhmonov. In: IY., Ed.; InTech: Rijeka, Croatia, $2016 ; 167-228$

33. Kitching M, Ramani M, Marsili E. Fungal biosynthesis of gold nanoparticles: Mechanism and scale up. Microb Biotechnol. 2015;8: 904-917.

34. Iravani S. Green synthesis of metal nanoparticles using plants. Green Chem. 2011;13:2638-2650.

35. Mondal A, Basu R, Das S, et al. Beneficial role of carbon nano tubes on mustard plant growth: an agricultural prospective. J Nano Research. 2011:13(10):4519-4528.
36. Bala N, Dey A, Das S, et al. Effect of hydroxy apetite nanorod on chickpea (Cicer arietinum) plant growth and its possible use as nano-fertilizers. Iranian Journal of Physiology. 2014;4(3):161-169.

37. Fraceto LF, Grillo R. de Medeiros GA, et al. Nanotechnology in agriculture: Which innovation potential does it have. Front Environ Sci. 2016;4:20.

38. Petosa AR., Rajput F, Selvam O, et al. Assessing the transport potential of polymeric nanocapsules developed for crop protection. Water Res. 2017;111:10-17.

39. González-Fernández R, Prats E, Jorrín-Novo JV. Proteomics of plant pathogenic fungi. J Biomed Biotechnol. 2010;2010:932527.

40. Rai M, Ingle A. Role of nanotechnology in agriculture with special reference to management of insect pests. Appl Microbiol Biotechnol. 2012;94(2):287-293.

41. Petosa AR, Rajput F, Selvam O, et al. Assessing the transport potential of polymeric nanocapsules developed for crop protection. Water Res. 2017;111:10-17.

42. DH Ling, BS Xing, Phytotoxicity of nanoparticles: Inhibition of seed germination and root growth. Environ. Pollut. 2007;50:243-250.

43. CLYan, W Qi, MR Hong. Effect of nanoparticles on the bacterial community of the cucumber phyllosphere. Chin J AgrBiotechnol. 2009;6(2):141-145.

44. Ma X, Geisler-Lee J, Deng Y, et al. Interactions between engineered nanoparticles (ENPs) and plants: phytotoxicity, uptake and accumulation. Sci Total Environ. 2010;408(16):3053-3061. 